\title{
Inventarisasi Tumbuhan Obat di Jalur Pendakian Gunung Ungaran
}

\author{
Muhamad Khoirurrais ${ }^{1}$, Ismail ${ }^{1}$, Baiq Farhatul Wahidah ${ }^{2}$ \\ ${ }^{1}$ Jurusan Pendidikan Biologi, Fakultas Sains dan Teknologi, UIN Walisongo Semarang \\ ${ }^{2}$ Program Studi Biologi, Fakultas Sains dan Teknologi, UIN Walisongo Semarang \\ Email: 1asrsya@gmail.com
}

\begin{abstract}
Mount Ungaran has a high varied vegetation which includes medicinal plants. The purpose of this study is to know the types of medicinal plants found in the hiking trails of Mount Ungaran. The method used in this research is the cruising method. The object of research was spermatophyta medicinal plants. Data collection techniques used in this study are observation, characterization and document review. The results of the study obtained 43 types of medicinal plants belonging to 30 families with the most families were Asteraceae family with the number of 5 species. But unfortunately these plants have not been maximally utilized by the surrounding community due to lack of community knowledge about the potential of these plants and their use especially as a medicinal plants.
\end{abstract}

Keywords: Plant inventaritation, medicinal plant, Mount Ungaran

\section{Pendahuluan}

Indonesia dikenal sebagai negara dengan sumber daya alam hayati terbesar ketiga di dunia setelah Brazil dan Afrika Selatan. Indonesia memiliki potensi keanekaragaman spesies yang tinggi. Indonesia diperkirakan mempunyai 19\% tanaman gymnospermae, 11\% tanaman berbunga, 13\% Tumbuhan paku, dan 9\% tumbuhan lumut dari semua jenis tumbuhan yang terdapat di dunia. Hal tersebut berpotensi besar sebagai peranan dalam penyediaan bahan baku tanaman obat (Fatmasari 2003).

Negara Indonesia sangat kaya akan berbagai jenis tumbuhan, terdapat kurang lebih 30 ribu jenis tumbuhan dari 40 ribu jenis tumbuhan yang terdapat di dunia. Terdapat sekitar 8000 jenis tumbuhan yang berkhasiat sebagai tumbuhan obat, tetapi baru sekitar 8001200 jenis tumbuhan obat yang dimanfaatkan sebagai obat tradisional atau jamu oleh masyarakat (Hidayat 2006). Hal ini mendorong peneliti untuk melakukan penelitian tentang keanekaragaman tanaman obat untuk menginventarisasi tumbuhan obat potensial agar dapat dimanfaatkan oleh masyarakat nantinya.

Tumbuhan obat tradisional di Indonesia mempunyai peran yang sangat penting terutama bagi masyarakat di daerah pedesaan yang fasilitas kesehatannya masih sangat terbatas. Nenek moyang kita mengenal obat-obatan tradisional yang berasal dari tumbuhan di sekitar pekarangan rumah maupun yang tumbuh liar di semak belukar dan hutan-hutan. Masyarakat sekitar kawasan hutan memanfaatkan tumbuhan obat yang ada sebagai bahan baku obat-obatan berdasarkan pengetahuan tentang pemanfaatan tumbuhan obat yang diwariskan secara turun-temurun (Hidayat 2012).

Usaha untuk penyebarluasan pemanfaatan tumbuhan obat merupakan salah satu hal yang perlu dilakukan. Dalam penyebarluasan hal tersebut perlu dilakukan pengenalan Tumbuhan obat beserta manfaatnya. Oleh karena itu perlu adanya inventarisasi tumbuhan obat agar dapat digunakan oleh masyarakat, misalnya di sekitar jalur pendakian Gunung Ungaran Jawa Tengah. 
Area pegunungan merupakan suatu tempat yang menarik untuk melakukan penelitian. Terdapat banyak sekali jenis vegetasi yang dapat ditemukan ditempat tersebut. Tanah yang subur serta udara yang sejuk menjadi faktor yang membuat kawasan tersebut banyak ditumbuhi tanaman (Utami 2013).

Gunung Ungaran memilik keanekaragaman vegetasi yang sangat bervariasi. Setidaknya terdapat sekitar 46 spesies kategori pohon, 17 kategori tiang, 27 kategori pancang, 19 jenis semai, dan 27 vegetasi lapisan bawah ditemukan pada ekosistem gunung ini. Gunung Ungaran mempunyai keanekaragaman hayati yang bervariasi yang dibedakan berdasarkan ketinggiannya. Tumbuhan sendiri terdiri dari berbagai jenis yaitu Spermatophyta, Pteryodophyta, dan Bryophyta. Tumbuhan jenis Spermatophyta banyak yang berkhasiat sebagai tumbuhan obat.

\section{Metode}

Penelitian ini dilakukan dengan menginventarisasi tumbuhan obat yang terdapat di jalur pendakian Gunung Ungaran melalui jalur Promasan sampai ke pos Bukaan pada ketinggian 1300-1500 m.dpl dan Kampus 2 UIN Walisongo Semarang.

Teknik pengumpulan data yang digunakan adalah observasi, karakterisasi, dan kajian dokumentasi. Data tumbuhan obat hasil observasi dikarakterisasi dengan melihat karakter atau sifat-sifat yang dimiliki tumbuhan obat yang ditemukan. Hasil dari karakterisasi digunakan untuk mengidentifikasi dan mengklasifikasikannya dengan dibantu teknik kajian dokumentasi.

\section{Hasil dan Pembahasan}

Berdasarkan data yang diperoleh dari analisis tumbuhan obat yang ditemukan di jalur pendakian Gunung ungaran ditemukan 43 spesies tumbuhan obat yang termasuk ke dalam kelompok tumbuhan Spermatophyta. Data tersebut diperoleh dari jalur pendakian Gunung Ungaran melalui jalur Promasan sampai ke pos Bukaan pada ketinggian 1300-1500 mdpl. Data
43 spesies tumbuhan tersebut selengkapnya disajikan pada Tabel 1.

Hasil observasi yang telah dilakukan diperoleh jumlah spesies tumbuhan sebanyak 43 spesies dari 30 famili. Tabel 1 menunjukkan bahwa jumlah spesies tumbuhan yang paling banyak berasal dari famili Asteraceae dengan jumlah lima spesies tumbuhan, kemudian diikuti oleh famili Solanaceae, Apiacea dan Rubiceae yang masing-masing berjumlah tiga spesies tumbuhan, kemudian famili Lauraceae, Myrtaceae dan Euphorbiaceae yang masingmasing berjumlah dua spesies tumbuhan, sedangkan sisanya pada setiap famili hanya ditemukan satu spesies tumbuhan.

Tumbuhan obat yang ditemukan tersebut berpotensi atau dapat digunakan oleh masyarakat sekitar sebagai obat tradisional untuk mengobati berbagai macam penyakit seperti demam, sakit kepala, sakit perut, diare, menurunkan panas, sakit gigi, diabetes mellitus, kanker, bronchitis, wasir, batuk, malaria, bengkak dan luka berdarah. Namun tumbuhantumbuhan tersebut belum dimanfaatkan secara maksimal oleh masyarakat sekitar dikarenakan kurangnya pengetahuan masyarakat mengenai potensi tumbuhan-tumbuhan tersebut dan pemanfaatannya.

Bagian tumbuhan yang dapat dimanfaatkan sebagai obat adalah daun, akar, batang, buah, biji dan bunga. Menurut Sari (2010), bagian tumbuhan herba yang digunakan untuk obat-obatan adalah akar, umbi, batang, daun, pucuk, bunga, dan buah. Dimana bagian tersebut ada yang dapat langsung digunakan sebagai obat dan ada pula yang harus melalui proses pengolahan. Cara penggunaan tumbuhan obat secara langsung dapat dilakukan dengan berbagai cara, diantaranya yaitu dengan merebus bagian tumbuhan yang akan digunakan kemudian air rebusannya diminum atau dengan menumbuk bagian tumbuhan yang akan digunakan.

Selain data vegetasi yang ditemukan di lokasi penelitian, dilakukan juga pengukuran 
Tabel 1. Tumbuhan obat yang ditemukan di Jalur Pendakian Gunung Ungaran

\begin{tabular}{|c|c|c|}
\hline No & Nama Tumbuhan & Famili \\
\hline 1 & Adas (Foeniculum vulgare) & Apiaceae \\
\hline 2 & Alang-alang (Imperata cylindrica) & Poaceae \\
\hline 3 & Alpukat (Persea gratissima) & Lauraceae \\
\hline 4 & Andong (Cordyline fruticosa) & Liliaceae \\
\hline 5 & Anting-anting (Acalypha australis) & Euphorbiaceae \\
\hline 6 & Awar-awar (Ficus septica) & Moraceae \\
\hline 7 & Babandotan (Hydrocotyle sibthorpioides) & Apiaceae \\
\hline 8 & Bayam Duri (Amaranthus spinosus) & Amaranthaceae \\
\hline 9 & Benalu Teh(Scurrula oortiana) & Loranthaceae \\
\hline 10 & Binahong (Anredera cordifolia) & Basellaceae \\
\hline 11 & Cemplonan (Drymaria cordata) & Caryophyllaceae \\
\hline 12 & Ciplukan (Physalis angulata) & Solanaceae \\
\hline 13 & Cocor Bebek (Bryophyllum pinnatum) & Rosaceae \\
\hline 14 & Daun Sendok (Plantago mayor) & Plantanginaceae \\
\hline 15 & Gandarusa (Justicia gandarussa) & Acanthaceae \\
\hline 16 & Harendong (Melastoma polyanthum) & Melastomaceae \\
\hline 17 & Iler (Coleus scutellariodes) & Labilatae \\
\hline 18 & Jambu Biji (Psidium guajava) & Myrtaceae \\
\hline 19 & Kayu Manis (Cinnamomum burmanni) & Lauraceae \\
\hline 20 & Kayu Putih (Melaleuca leucadendron) & Myrtaceae \\
\hline 21 & Kecombrang (Nicolaia speciosa) & Zingiberaceae \\
\hline 22 & Kina (Cinchona ledgeriana) & Rubiaceae \\
\hline 23 & Kirinyuh (Eupatorium inulifolium) & Asteraceae \\
\hline 24 & Kopi Robusta (Coffea arabica) & Rubiaceae \\
\hline 25 & Krokot (Portulaca oleraceae) & Portulacaceae \\
\hline 26 & Kumis Kucing (Orthosiphon spicatus) & Lamiaceae \\
\hline 27 & Melati (Jasminum multiflorum) & Jasminaceae \\
\hline 28 & Meniran (Phyllanthus urinaria) & Euphorbiaceae \\
\hline 29 & Orok-orok (Crotalaria incana) & Fabaceae \\
\hline 30 & Pacar Air (Impatiens balsamina) & Balsaminaceae \\
\hline 31 & Pegagan (Centella asiatica) & Apiaceae \\
\hline 32 & Petai Cina (Leucaena glauca) & Mimosaceae \\
\hline 33 & Randa Tapak (Taraxacum officinale) & Asteraceae \\
\hline 34 & Rumput Mutiara (Hedyotis corymbosa) & Rubiaceae \\
\hline 35 & Sawi (Vernonia cinerea) & Asteraceae \\
\hline 36 & Sidaguri (Sida rhombifolia) & Malvaceae \\
\hline 37 & Tebu Wulung (Saccarum officinarum) & Cyperaceae \\
\hline 38 & Teh (Cammelia sinensis) & Theaceae \\
\hline 39 & Tembelekan (Lantana camara) & Verbenaceae \\
\hline 40 & Terong Belanda (Solanum betaceum) & Solanaceae \\
\hline 41 & Terong Ranti (Solanum nigrum) & Solanaceae \\
\hline 42 & Tusuk Konde (Heliotropium indicum) & Asteraceae \\
\hline 43 & Urang-aring (Eclipta alba) & Asteraceae \\
\hline
\end{tabular}


Tabel 2. Pengukuran parameter lingkungan pada ketinggian yang berbeda

\begin{tabular}{lccc}
\hline \multirow{2}{*}{ Parameter Lingkungan } & \multicolumn{3}{c}{ Hasil Pengukuran pada Ketinggian (mdpl) } \\
\cline { 2 - 4 } & 1300 & 1430 & 1520 \\
\hline Temperatur Udara $\left({ }^{\circ} \mathrm{C}\right)$ & 21,5 & 24,1 & 24,7 \\
Kelembaban Udara (\%) & 73 & 70 & 68 \\
Intensitas Cahaya (Lux) & 745 & 975 & 1499 \\
PH Tanah (\%) & 6,2 & 6,3 & 6,4 \\
\hline
\end{tabular}

beberapa parameter lingkungan seperti suhu, kelembaban udara, derajat keasaman tanah $(\mathrm{pH})$ dan intensitas cahaya. Data parameter lingkungan digunakan sebagai data tambahan pendukung hasil penelitian.

Pengukuran parameter lingkungan dilakukan pada rentang waktu 14.00-16.30 WIB. Data parameter lingkungan diperoleh dari tiga ketinggian yang berbeda. Setiap ketinggian dilakukan pengukuran sebanyak 3 kali pada tempat yang berbeda kemudian diambil rata-ratanya. Data hasil pengukuran parameter lingkungan di jalur pendakian Gunung Ungaran disajikan pada Tabel 2.

Berdasarkan hasil pengukuran parameter lingkungan yang dilakukan pada area pengamatan diperoleh gambaran kondisi lingkungan yang diamati di jalur pendakian Gunung Ungaran selama penelitian dilakukan. Hasil pengukuran pada setiap ketinggian menunjukkan bahwa temperatur udara berkisar antara 21,5-24,7 ${ }^{\circ} \mathrm{C}$. Kelembaban udara berkisar antara 68-73 \%. Intensitas cahaya berkisar antara 745-1499 lux. pH tanah berkisar antara 6,2$6,4 \%$, yang menunjukkan tanah di area pengamatan tersebut bersifat asam.

\section{Simpulan}

Berdasarkan data yang diperoleh menunjukkan bahwa tumbuhan obat yang ditemukan di jalur pendakian Gunung Ungaran sebanyak 43 spesies tumbuhan dari 30 famili. Jumlah spesies tumbuhan yang paling banyak ditemukan berasal dari famili Asteraceae yaitu sebanyak lima spesies tumbuhan, Namun tumbuhan-tumbuhan tersebut belum dimanfaatkan secara maksimal oleh masyarakat sekitar dikarenakan kurangnya pengetahuan masyarakat mengenai potensi tumbuhan-tumbuhan tersebut dan pemanfaatannya.

\section{Daftar Pustaka}

Fatmasari M. 2003. Studi Potensi Tumbuhan Obat di Kawasan Hutan Pendidikan Gunung Walat. Skripsi. Bogor: Institut Pertanian Bogor.

Hidayat D, Hardiansyah G. 2012. Studi keanekaragaman jenis tumbuhan obat di kawasan IUPHHK PT Sari Bumi Kusuma Camp Tontang Kabupaten Sintang. Vokasi. 8(2): 61-68.

Hidayat S. 2006. Tumbuhan obat Langka di Pulau Jawa: Populasi dan Sebaran. Pusat Konservasi Tumbuhan Kebun Raya Bogor.

Sari N. I. 2010. Studi Etnobotani Tumbuhan Herba pada Masyarakat Karo di Kawasan Taman Nasional Gunung Leuser (Studi Kasus di Desa Telagah Kecamatan Sei Bingai Kabupaten Langkat) dalam waktu yang ditetapkan. Skripsi. Medan: Universitas Sumatera Utara.

Utami P. 2013. Umbi Ajaib Tumpas Penyakit Kanker, Diabetes, Hipertensi, Stroke, Kolesterol, dan Jantung. Jakarta: Penebar Swadaya. 